\title{
PHARMACIST-STRENGTHEN ADHERENCE TO ANTIRETROVIRAL THERAPY AND THE CONTRIBUTING FACTORS AMONG HIV-INFECTED PAEDIATRIC PATIENTS IN NIGERIA
}

\author{
Shakirat Tyabo Bello
}

\begin{abstract}
Introduction: Children adherence to Highly Active Antiretroviral Therapy (HAART) not only creates a problem for the treated children, but also for their caregivers and healthcare providers. The objective of this study was to determine adherence level and evaluate factors associated with better drug adherence among HIV-infected children in Nigeria. Methods: Adherence to HAART was determined prospectively among HIV-infected children attending HAART Clinic in the University of Ilorin Teaching Hospital, Ilorin, Nigeria. Adherence level was measured using self-reported method and patients medical folders. Logistic regression analysis was used to assess factors associated with better drug adherence among the children. Results: In the eighty children studied, mean age at baseline was $2.16 \pm 0.74$ years and $60 \%$ were males. Baseline adherence level was $74.0 \%$ which improved to $98.0 \%$ over the course of 8-months follow-up intervention by the pharmacist $(\mathrm{p}<0.043)$. Forgetfulness of caregivers to administer antiretroviral medication at the right time to the children was the highest reason for non- adherence. Factors associated with better drug adherence were duration on HAART (OR 1.201; 0.253-1.144, $p<0.003$ ), age (OR 0.540; 0.162-1.006, $p<0.001$ ), type of regimen (OR 0.222; 0.134-1.356, $p<0.046$ ) and heavier weights (OR 1.559; 0.403-1.826, $p$ $<0.023)$. Conclusions: Following pharmacist's intervention coupled with other factors, adherence to HAART was strengthened with significant improvement in the children medication-taking behaviour.
\end{abstract}

Keywords: Children, paediatric, adherence, caregivers, pharmacist, UITH

Received: 08 July 2016

Accepted: 28 December 2016

\section{Introduction}

In accordance with the estimates in 2015 by UNAIDS, approximately36.7 million individuals were infected with Human Immunodeficiency Virus (HIV) globally, while 35 million died from AIDS-related sicknesses from the commencement of the scourge. Between 2010 and 2015, newly HIV-infected cases dropped by $6 \%$, and only $150,000(50 \%)$ children were infected in comparison with 290,000. In Nigeria, around 3.5 million individuals were infected with HIV in 2015, with 1.8 million orphans of between 0 and 17 years of age. Meanwhile, about 260, 000 children needed antiretroviral drugs $(\mathrm{ARV})^{1}$. Transmission from mother to child is the major cause of the infection among children below the age of 15 years. About $15-30 \%$ of infants born from HIV infected mothers were found to be infected during pre and post natal periods ${ }^{2}$. The aims in remedying HIV-infected paediatric patients include; decreasing HIV-linked morbidity and mortality, reinstating and/ or conserving immune function, reducing drug-associated toxicity, enhancing quality of life, extremely and robustly suppressing virus-related duplications as well as retaining usual neurocognitive improvement and physical advancement ${ }^{1}$. Highly Active Antiretroviral therapy (HAART) has incredibly enhanced the long-standing existence of children infected with HIV, and better results depend on a high degree of adherence to treatment ${ }^{3}$. Adherence is referred to as the rate at which a person takes his/her medicine, keep to diet and changes in lifestyle, based on health recommendations ${ }^{4}$. Unlike adults, the infants rely

Designation of Clinical Pharmacy and Pharmacy Practice, University of Ilorin, Ilorin Nigeria

Bangladesh J Medicine 2017; $28: 5-12$ 
on caregivers for drugs when ill ${ }^{5}$. Children could reject medication as a result of poor tastiness, nasty flavour or pill burden ${ }^{6,7}$. Other factors could be poor knowledge of the significance of ARV drugs by the caregivers/parents and long term drug effects. The caregivers might not be ready to disclose to the child his/her HIV status. Moreover, non-adherence to HAART in paediatric patients is related to income, caregiver-child communication, caregiver health belief, caregiver type, depression, forgetfulness, stigma and stress ${ }^{8}$. All of these factors can create problems in managing their medications particularly if the child is in school and the parent gone for work ${ }^{9-}$ 11. Resistance to HIV infection develops whenever the ARV blood concentration is below the minimum inhibitory concentration, therefore, optimal adherence to HAART is essential by ensuring that medications are rightly and regularly administered ${ }^{11,12}$. Evaluating and facilitating adherence are significant to efficient antiretroviral prevention and treatment of drug resistance ${ }^{13}$. To strengthen adherence to HAART in children infected with HIV, it is crucial to ascertain factors that cause non-adherence and examine the likely interventions that could improve adherence. In spite of this, a research was conducted to measure the level of adherence among paediatric patients on HAART and contributing factors related to better medication adherence.

\section{Setting}

The research was conducted in the Highly Active Antiretroviral Therapy (HAART) Clinic of the University of Ilorin Teaching Hospital (UITH), Ilorin, the capital of Kwara State in the North-Central geopolitical zone of Nigeria. UITH was set up by Federal Government of Nigeria on $2^{\text {nd }}$ May, 1980 and consists of 17 clinical and 11 non-clinical Departments. The setting offers medical services to the native people of Kwara, Osun, Ondo, Kogi, Oyo and Lagos States. The Management Science for Health (MSH), an American based Non-Governmental Organization (NGO) supports patients with funds and medical materials at the hospital, especially in tuberculosis therapy, child and reproductive health, as well as Human Immunodeficiency Virus (HIV) and Acquired Immune-Deficiency Syndrome (AIDS) therapy and care. The NGO supplies free antiretroviral and opportunistic infection drugs, free laboratory tests (CD4 counts, hepatitis, tuberculosis and HIV tests), basic care package (net, condoms, buckets and soaps) and Computer system for Electronic Medical Record (EMR).The NGO also assists in prevention of mother to child transmission of HIV by providing delivery packs and dried blood spot kit tests, subsidizing antenatal fee and provision of plumpy nuts for the malnourished HIV-infected babies.

Zidovudine + lamivudine + efavirenz, tenofovir + lamivudine + efavirenz, zidovudine + lamivudine + nevirapine, emtricitabine + abacavir + lopinavir/ ritonavir, abacavir + lamivudine + lopinavir/ritonavir and tenofovir + lamivudine + lopinavir/ ritonavir were the combination therapy of ARV drugs in this setting. United Nation in collaboration with National Agency for Control of AIDS also provides opportunistic infectious drugs to the Clinic. These include tablet ciprofloxacin, capsule amoxicillin, tablet chlorpheniramine, tablet cotrimoxazole, capsule fluconazole, clotrimozole vaginal pessaries and creams.

\section{Study Population}

All HIV-infected children on HAART in UITH were enrolled for the study. "Caregiver" in this study is referred to as an adult who broughtan HIV infected child for clinical diagnosis and understood the administration of the child's medication. The subjects eligible in this study were children between 1 and 14 years, diagnosed and documented as HIV-positive at the HAART Clinic. Others are HIV paediatric patients on HAART for one year and above, those who gave approval to participate in the study and refilled their medical prescriptions in the Pharmacy Unit of the hospital. Those excluded were paediatric patients on hospital admissions, children above 14 years and those thatwere yet to be confirmed as HIV positive.

\section{Sample and Sampling Technique}

The minimum sample size was assessed based on the statistical formula of Fisher according to ${ }^{14}$;

$\mathrm{n}=\mathrm{Z}^{2} \mathrm{pq} / \mathrm{d}^{2}$.

Where: $n=$ Minimum sample size for a statistically significant survey, $Z$ = Standard normal deviant set at $1.96, q=1-p, q=$ complement of $p, p=$ proportion in the target population usually $50 \%(0.5)$ and $\mathrm{d}=$ degree of accuracy of 0.05 .

Based on the above formula, the population sample size for greater than 10,000 was calculated as follows; $\mathrm{n}=\left(1.96^{2} \times 0.5 \times 0.5\right) / 0.05^{2}$

$\mathrm{n}=384$

Since the population of HIV infected children on HAART in UITH was 90, the sample size for a population less than 10,000 was calculated using;

$\mathrm{nf}=\mathrm{n} /(1+\mathrm{n} / \mathrm{N})$.

Where,

$\mathrm{nf}=$ Desired sample size

$\mathrm{n}=$ sample size for population greater than 10,000 (384)

$\mathrm{N}=$ estimate of the study population (90) 
Therefore,

$\mathrm{nf}=384 /(1+384 / 90)$

$\mathrm{nf}=72$

$10 \%$ was added to the sample size to justify loss to follow up.

Therefore, the sample size of the children used for this study was 80 .

\section{Study Design}

The study design was a longitudinal, single-centre retrospective and prospective study carried out in the HAART Clinic of the University of Ilorin Teaching Hospital (UITH), Ilorin, Nigeria.

Ethical approval was received from the Ethics and Research Committee of UITH (Protocol no: UITH/CAT/ 189/VOL.19A/401)and University of Ilorin Ethical Review Committee, Ilorin, Kwara State, Nigeria to conduct the study. Furthermore, written and oral informed consents/assents were received from the caregivers and children. Enrolled into the study were eighty paediatric children who have been confirmed to be HIV-infected and on HAART.

The significance of the study was properly emphasized by the pharmacist to the caregivers and the children. Study visits were arranged on the child's medical appointments schedule. Social demographic profile, clinical and treatment variables of the children were extracted from patients' medical folders. Before commencing the study, questionnaires were distributed to ten paediatric patients at random to validate the study instruments. Cronbach reliability test of 0.71 was obtained to ensure consistency in the items of the questionnaire. The data set obtained involved patients' socio-demographic, treatment variables, clinical variables and oral interview of the children/caregivers on self-reported adherence level. Patients' evaluation of adherence level and factors associated with non-adherence in these children were also investigated. The interview was conducted in Yoruba (local language), Pidgin and English languages. Pharmaceutical counselling of the children and caregivers was conducted at every two-month when refilling pharmacy prescriptions. Each paediatric patient/caregiver in this study was counselled on ARV medication adherence by the pharmacist-resource at baseline (0-month) and strengthened at every twomonth for eight months on Clinic Visit.

\section{Measurement of Adherence Level}

Self-reporting technique was implemented to verify the adherence level of children on HAART. The caregivers were interviewed on adherence by asking them to recollect number of pills the children took in the past seven days, and also how they administered drugs in the children during the last 30 days. In this approach, adherence was termed as administering $95 \%$ of prescribed medication doses in a month, which resulted to omitting only one dose within 30 days for once daily dosing. Adherence levels were determined by self-reporting through the children/ caregivers based on the use of quantity of the treatment doses unused in the last seven and thirty days representing seven-day and thirty-day recalls respectively. Adherence result was calculated as the percentage of drugs administered compared with those prescribed. Best adherence is achieved when the entire dosage of antiretroviral drugs administered is more than $95 \%$, while less than 95\% was recognized as non-adherence.

\section{Pharmacist's intervention}

The interventions provided to the patients/caregivers include; the significance of adhering wholly to the medication regimen, the risk of developing drug resistance to ARVs, the advantage of proper timing of drugs, importance of pill-taking with/out meals, management of mild drug side effects, awareness on long-term toxicities of ARV drugs and loss of alternative drugs for treatment of the infection if available drugs failed. All the adherent and nonadherent children were counselled at every 2-month for 8 months.

\section{Statistical Analysis}

Statistical tests were carried out using descriptive statistics including means, percentages and frequencies. Identification of variables associated with better medication adherence was determined using regression analysis with PROC GLM model of SAS ${ }^{15}$. A P-value of $<0.05$ was regarded as significant in all the analysis. Cronbach reliability test was used for consistency in the items of the questionnaire.

\section{Results:}

One fifth ${ }^{16}$ of the children were within the age bracket of 1 to 5 years, though more than one third of the children(36.2\%) were within 11 and 14 years (TableI). About one half of the children fell between the age of 6 and 10 years.

Among the eighty children that consented to participate in the research, more than one third had weights ranging between 21 and $30 \mathrm{~kg}$, though very few $(6.3 \%)$ fell in the range of $40-50 \mathrm{~kg}$ (Table-II). 
Table-I

Percentage distribution of the children by age

\begin{tabular}{lcc}
\hline Age (years) & Frequency $(\mathrm{n})$ & Percentage $(\%)$ \\
\hline $1-5$ & 16 & 20.0 \\
$6-10$ & 35 & 43.8 \\
$11-14$ & 29 & 36.2 \\
Total & 80 & 100.0 \\
\hline
\end{tabular}

$\mathrm{N}=80$, Mean $=4.16 \pm 0.74$.

Table-II

Weight variables of HIV-infected children

\begin{tabular}{lcc}
\hline Weight $(\mathrm{kg})$ & Frequency $(\mathrm{n})$ & Percentage $(\%)$ \\
\hline $10-12$ & 27 & 33.7 \\
$21-30$ & 32 & 40.0 \\
$31-40$ & 16 & 20.0 \\
$40-50$ & 5 & 6.3 \\
\hline Total & 80 & 100.0 \\
\hline
\end{tabular}

Sixty five percent of the patients were on HAART between 1 and 5 years and few 3(3.7\%) were on HAART for 11-15 years. The mean duration on HAART was 2.39 years (Table III). In this study, combination of nevirapine, lamivudine and zidovudine was mostly $(71.3 \%)$ taken by the children as first-line drug (Table 4).. The most prominent adverse effect identified among the eight patients that reported adverse drug effects was rashes (Table-V).

Table-III

Duration on HAART

\begin{tabular}{lcc}
\hline Years & $\mathrm{N}=80$ & $\%$ \\
\hline $1-5$ & 52 & 65.0 \\
$6-10$ & 25 & 31.3 \\
$11-15$ & 3 & 3.7 \\
\hline
\end{tabular}

$\mathrm{N}=80$, Mean $=2.39, \mathrm{SD}=0.56$

Table IV

Types of HAART regimen used by the children

\begin{tabular}{lcc}
\hline Regimen & $\mathrm{N}=80$ & $\%$ \\
\hline First-Line Regimen & & \\
Zidovudine/Lamivudine/Nevirapine & 57 & 71.3 \\
Zidovudine/Lamivudine/Efavirenz & 14 & 17.4 \\
Tenofovir/Lamivudine/Efavirenz & 1 & 1.3 \\
Second-Line Regimen & & \\
Tenofovir/Lamivudine/Lopinavir/ritonavir & 4 & 5.0 \\
Zidovudine/Lamivudine/Lopinavir/ritonavir 1 & 1.3 \\
Abacavir/Lamivudine/Lopinavir/ritonavir & 2 & 2.4 \\
Abacavir/Emtricitabine/Lopinavir/ritonavir & 1 & 1.3 \\
\hline
\end{tabular}

Table-V

Adverse effects of ARVs among the children

\begin{tabular}{lcc}
\hline Adverse effects & $\mathrm{N}=8$ & Percentage (\%) \\
\hline Fever & 1 & 1.3 \\
Rashes & 3 & 3.8 \\
Red eye & 1 & 1.3 \\
Body weakness & 1 & 1.3 \\
Abdominal pain & 2 & 2.5 \\
\hline
\end{tabular}

At baseline, the adherence level was $74.0 \%$ as reported by the children and caregivers. Following pharmacist's intervention, the adherence level increased to $98.0 \%$ at the 8 months of follow-up (Figure 1)

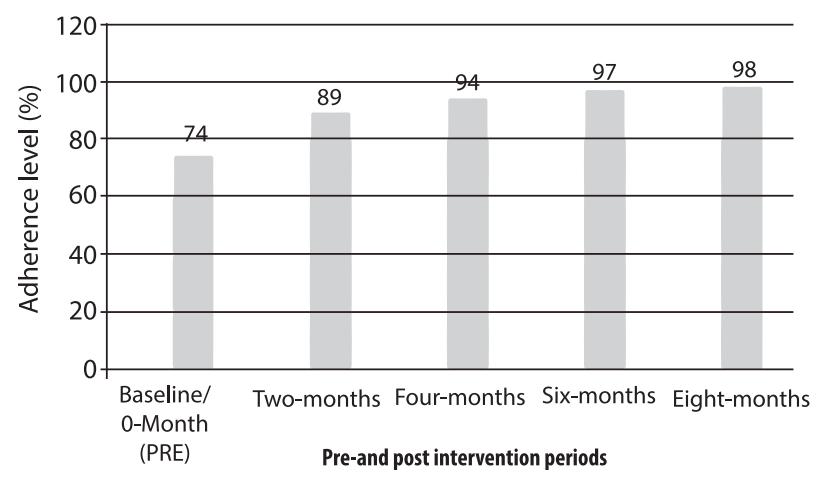

Fig.-1: Adherence level prior and post intervention

Forgetfulness by the caregivers was the highest reason for non-adherence (Table VI).

Table-VI

Reasons for non-adherence to HAART among the children and caregiver

\begin{tabular}{lcc}
\hline Reasons Caregivers & N (\%) & Children \\
\hline Forgetfulness & $32(40.0)$ & “ \\
Child refusal & $22(27.4)$ & “ \\
Travelling & $4(4.9)$ & “ \\
Undisclosed HIV status & $11(13.7)$ & “ \\
School attendance & $6(8.1)$ & “ \\
Peer group influence & $5(5.9)$ & “ \\
\hline
\end{tabular}

Regression analysis was used to determine factors associated with better drug adherence in the children studied (Table-VII). 
Table-VII

Logistic regression analysis of factors associated with adherence to antiretroviral treatment in HIV children

\begin{tabular}{lcc}
\hline Factors & OR $(95 \%$ CI $)$ & P-value \\
\hline Duration on ART & $1.201(0.253-1.144)$ & $0.003^{*}$ \\
Less than 5 years & $1.000(0.427-2.062)$ & 0.182 \\
Greater than 5 years & & \\
Religion & $1.229(0.212-2.931)$ & 0.201 \\
Islam & $1.000(1.111-2.941)$ & 0.344 \\
Christian & $1.208(0.341-4.283)$ & 0.462 \\
Age (Years) & $1.224(0.226-1.368)$ & 0.609 \\
1-5 & $0.54(0.162-1.006)$ & $0.001^{*}$ \\
6-10 & $1.559(0.414-5.863)$ & 0.511 \\
11-14 & $0.488(0.112-1.316)$ & 0.262 \\
Weight (kg) & $1.000(0.403-1.826)$ & $0.003^{*}$ \\
$</=30$ & & \\
$>30$ & $1.061(0.404-2.322)$ & 0.463 \\
Type of regimen & $0.222(0.134-1.356)$ & 0.336 \\
\hline First line therapy & & \\
Second line therapy & & \\
\hline
\end{tabular}

*Statistically Significant at $\mathrm{P}<0.05$.

\section{Discussion:}

The average age of the children was $4.16 \pm 0.74$ years. This research was comparable to the reports of ${ }^{16}$ in Mali who observed that most of the children were between ages of 5 and 9 years. Earlier works of ${ }^{17}$ in Nigeria, showed that a good number (64\%) of the children were less than six years old.

In this study, heavier weights are significantly associated with improvement in medication adherence. The findings ${ }^{18}$ were inconsistent with this study and showed that medication adherence was not significantly associated with weight increase in the children. Most of the children had weights ranging from $21-40 \mathrm{~kg}$ which corresponded to age range of 6 to10 years. The findings of a study ${ }^{19}$ revealed that the weights of the studied HIV-infected children were almost corresponding to that of uninfected children. In the present study, the adherence rate at baseline was $74.0 \%$, and increased to $98.0 \%$ on provision of pharmaceutical counselling by the resource pharmacist. Medication adherence level post intervention found in the present study was higher than the study of ${ }^{20}$ with $83 \%$, with $88.3 \%^{21}, 81.2 \%{ }^{22}$ for, $70 \%{ }^{23}$ for and $85.5 \%{ }^{24}$ for. These variations may be accorded to activities that have been undertaken by government in the study setting to enhance the
ART service. The other rationale could be due to dissimilarity in assessment methods and type of HAART regimen used in the centre of study. Also, this study used only self-report method to measure adherence level, but multi-method adherence assessment including self-report, the visual analogue scale, and pill count were used in other studies.

The present study followed the World Health Organization Antiretroviral Therapy (WHO ART) guideline for treatment of HIV/AIDS ${ }^{25}$ that in a setting where stavudine regimens are used as the principal option for starting ART a progressive plan to move towards zidovudine based first-line regimen should be developed based on an assessment of cost, toxicity and feasibility standard of treatment. Unlike the study of 26 who discovered that majority (59\%) of subjects were on stavudine, lamivudine and nevirapine.

Abdominal pain, fever, red eye and body weakness were other effects observed. Also, the findings of 27,28 were consistent with the present study whereby a small proportion of the children had adverse effects. The findings of ${ }^{29}$ reported that non-adherence to HAART is facilitated by adverse drug effects.

This study was in line with earlier studies of 27,28 who reported 95\% adherence level among children/ caregiver in rural China. The result of this study is good as 95\% adherence level required for optimal suppression of the virus among HIV-infected paediatric patients was achieved. The possible explanation could probably due to free ARV drugs, mild and amenable adverse drug effects as well as pharmaceutical counselling proffered to the children/ caregivers during follow-up study. Good clinical, immunological and virological outcomes from HAART rely on high rates of adherence to therapy ${ }^{3}$. These outcomes include reduction of HIV-related mortality and morbidity, restoring and/or preserving immune function, improving quality of life, maximally and durably suppressing viral replication, maintaining normal physical growth and tremendously improved the long-term survival of HIV-infected children ${ }^{30}$.

Forgetfulness by the caregivers was the highest reason for non-adherence This finding is in line with the study of ${ }^{31,32}$ in which forgetfulness was a major reason for not adhering to HAART. Other reasons for non-adherence as reported by the children and caregivers were child refusal, school attendance, travelling, undisclosed HIV status and peer group influence. Child related factors include drug refusal, school attendance and peer group influence. The result of study ${ }^{33}$ was in line with the present study. Long work hours of caregivers was linked with nonadherence in children as observed by the study of ${ }^{34}$ 
which was not in line with this study that reported travelling in this study. Contrarily to this study, was the work of 5 in Kano who reported financial constraints, unavailability of HAART and inaccessibility to medications were reasons for nonadherence among the children studied. Furthermore, the previous studies of $24,28,35,36$ revealed that stigma, drug side effects, inadequate HAART, exorbitant costs of treatment were parameters that influenced adherence to HAART. The ARV drugs provided at no cost in the setting of this study could possibly contributed to optimal adherence level attained.

Treatment, socio-demographic and clinical characteristics represented the independent variables and HAART adherence as the dependent factor in the regression analysis. The following factors were found to significantly improve adherence among these children; age (OR 0.541; 0.162-1.006, p < 0.001), heavier weights (OR 1.559; 0.403-1.826, $\mathrm{p}<0.023$ ), duration on HAART (OR 1.201; 0.253-1.144, p < 0.003) and type of regimen (OR 0.222; 0.134-1.356; $\mathrm{p}<0.046$ ) as shown in the table below. Possible reasons for decline in adherence with increase in child's age could be attributed to peer group influence, stigmatization, pill burden, complex dosing, children getting to know their HIV status and lacking knowledge of ARV medications. In Ethiopia, the study of ${ }^{22}$ reported similar findings. However, the previous studies of 3.5.37.38 in Brazil, Nigeria, Togo and Italy were inconsistent with the present findings. In addition, HAART duration is significantly associated with better drug adherence (OR 1.2; 0.253-1.144, $\mathrm{p}<003$ ). The results of 39,40 in Nigeria were contrary as duration of HAART was not linked to drug adherence. The only factor not significantly associated with better drug adherence in this study was religion.

\section{Conclusion}

Pharmaceutical interventions proffered by the pharmacist among other factors strengthened the adherence level of these children.

\section{Acknowledgements}

We appreciate the UITH management for allowing us to conduct the research including Pharm. (Mrs) G. Medubi, the Head of Department of HAART Pharmacy Unit.

\section{References}

1. UNAIDS. UNAIDS report on the global AIDS epidemic. Available at: http://www.unaids.org/ globalreport/global_report.htm. Accessed on 09 December, 2016.Epub 2016/01/03.

2. UNAIDS. UNAIDS report, 2010. Available at: http:/ /www.unaids.org/globalreport/Global_report.htm.
Accessed on 12 December, 2016. Epub 2010/ $11 / 09$.

3. WHO. Global HIV/AIDS response: Epidemic update and health sector progress towards universal access - progress report 2011. Geneva: World Health Organization. Epub 2011/10/23.

4. Haberer J. and Mellins C.. Pediatric adherence to HIV antiretroviral therapy. Curr. HIV/AIDS Rep, 2006: 6(4):194-200.Epub 2006/01/11.

5. Mukhtar-Yola M., Adeleke S., Gwarzo D. and LadanZ.F.. Preliminary investigation of adherence to antiretroviral therapy among children in Aminu Kano Teaching Hospital, Nigeria. Afr. J. AIDS Res., 2006: 5(2): 141-144. Epub 2005/11/13.

6. Skovdal M., Campbell C., Madanhire C., Nyamukapa C. and Gregson S. Challenges faced by elderly guardians in sustaining the adherence to antiretroviral therapy in HIV-infected children in Zimbabwe. AIDS Care, 2011: 23(8):957-964.Epub $2011 / 08 / 22$.

7. Vreeman R.C., Nyandiko W.M. and Liu H. Measuring adherence to antiretroviral therapy in children and adolescents in western Kenya. J. Int/ AIDS Soc., 2014:17:12-27.Epub 2014/05/23.

8. Naar-King S., MontepiedraG.and Nichols S. Allocation of family responsibility for illness management in pediatric HIV. J. Pediatr. Psychol., 2009: 34(2): 187-194.Epub 2009/08/21.

9. Cluver L.D., Hodes R.J. and Toska E"HIV is like a tsotsi. ARVs are your guns": Associations between HIV-disclosure and adherence to antiretroviral treatment among adolescents in South Africa. AIDS,. 2015: 29(1): 57-65.Epub 2015/03/12.

10. Mghamba, F. M., Minzi, O. M. S., Massawe, A. and Sasi, P. Adherence to antiretroviral therapy among HIV infected children measured by caregiver report, medication return, and drug level in Dar Es Salaam, Tanzania. BMC Pediatrics, 2013: 13: 132-141.Epub 2013/07/06.

11. Arage, G., Tessema, G.A. and Kassa, H. Adherence to antiretroviral therapy and its associated factors among children at South Wollo Zone Hospitals, Northeast Ethiopia: A cross-sectional study. BMC Public Health, 2014: 14:365-376. Epub 2014/08/ 09.

12. Shah, C.A. Adherence to high activity antiretroviral therapy (HAART) in paediatric patients infected with HIV: Issues and Interventions. Indian J. Pediatr., 2007:74(1): 55-60.Epub 2007/09/27.

13. FMHE. Guidelines for paediatric HIV/AIDS care and treatment in Ethiopia. Addis Ababa, Ethiopia: Federal HIV/AIDS Prevention and Control Office, Federal Ministry of Health, 2008, Ethiopia.Epub 2008/12/03. 
14. Araoye, M.O. (2004). Research Methodology with Statistics for Health and Social Sciences ( $1^{\text {st }}$ edition) (pp.115-120). Ilorin, Nigeria: Nathadex Publishers.

15. SAS. 2011. Statistical analysis system (SAS) software for windows version 9.2. Vol. 1. SAS Institute. Cary, N.C. USA.

16. Omar A.A., korotoumou D, Dembélé J.P., SamakéL. Sidibé I., Togo B., Sylla M., Tounkara A., Dao,S. and Tulkens P.M. Adverse drug reaction to antiretroviral therapy; prospective study in children in Sikasso (Mali). J. Pediatr. Pharmacol. Ther., 2012; 17(4): 382-388.

17. Ebonyi A. O., Oguche S., Emeka U. Okpe E.S.E., Agbaji O. O., Sagay S. A., Okonkwo P., Idoko J. A. and Kanki P. Risk factors for first-line antiretroviral treatment failure in HIV-1 infected children attending Jos University Teaching Hospital, Jos, North Central Nigeria. British Journal of Medicine and Medical Research; 2014; 4(15):2983-2994.

18. WHO (2013). Consolidated guidelines on the use of antiretroviral drugs for treating and preventing HIV infection: Recommendations for a public health approach. (www.who.int/hiv/pub/guidelines / arv2013/annexes). Retrieved on14 December, 2016.

19. Puthanakit T., Aurpibul L., Oberdorfer P., Akarathum N., Kanjananit S., Wannarit P., Sirisanthana T. and Sirisanthana V. Hospitalization and mortality among HIV- infectedchildren after receiving highly active antiretroviral therapy. CID, 2007; 44: 599-604.

20. Pensi T. Fixed dose combination of lamivudine, stavudine and nevirapine in treatment of peadiatric HIV-infection. Indian Pediatrics, 2007; 44: 519521.

21. Wang $X$. and Wu Z. Factors associated with adherence to antiretroviral therapy among HIV/AIDS patients in rural China. AIDS, 2007; 21: 149-155.

22. Dachew B.A., Tesfahunegn T.B. and Birhanu A.M. Adherence to highly active antiretroviral therapy and associated factors among children at the University of Gondar Hospital and Gondar Poly Clinic, Northwest Ethiopia: a cross-sectional institutional based study. BMC Public Health. 2014; 14: 875-890.

23. WHO. Panel on antiretroviral guidelines for adults and adolescents. Guidelines for the use of antiretroviral agents in HIV-1-infected adults and adolescents. Department of Health and Human Services. Available at http://aidsinfo.nih.gov/ contentfiles / lvguidelines / AdultandAdolescen tGL.pdf. Accessed on December, 2012; 17, 2016.

24. WHO/CDC. Information and data for above growth charts sourced from The World Health Organization, Gerontology Research Center (National Institutes of Health, USA), and the U.S. Centers for Disease
Control and Prevention (https://www.disabledworld.com/artman / publish / height-weightteens.shtml). Assessed on 20th November, 2016.

25. Awel M. Antiretroviral adherence and its detriments among people living with HIV/AIDS on highly active antiretroviral therapy in two hospitals of Ormoyia Regional State Ethopia. Ethiopian Public Health Association (EPHA) extract from EPHA sponsored Master Thesis on HIV/AIDS. 2008.

26. Marcos E., Worku A. and Davey G. (). Adherence to RT in PLWHA at Yirgalem hospital, South Ethiopia. The Ethiop. J. Health Dev., 2008; 22: 174-179.

27. Abdulwadud O., Admassu K., Endale A., Tesfaye N. and Teshome G. (). Retrospective review of antiretroviral therapy program data in accredited private hospitals in Addis Ababa City Administration. Ethiop J. Health. Dev. 2011; 25: 110-115.

28. Wagner G.J. (2004). Predictors of Antiretroviral Adherence as measured by self report. Electronic monitoring, and medication diaries. AIDS patient care STD, 16: 599-608.

29. Uzochukwu B.S.C., Onwujekwe O.E., Onoka A.C., Okoli C., Uguru N.P. and Chukwuogo O.I. Determinants of non-adherence to subsidized antiretroviral treatment in southeast Nigeria. Health Policy Plan, 2009; (3):189-196.

30. Buchanan A.L., Montepiedra G., Garvie P.A., Storm D.S., and Nichols S.L. Barrier to medication Adherence in HIV infected children and youth based on self and caregivers report. Paediatrics; 2012; 129(5): 1244-1251.

31. Okoronkwo I., Okeke U., Chinweuba A., and Iheanacho P. (2013). Non-adherence factors and sociodemographic characteristics of HIV-infected adults receiving antiretroviral therapy in NnamdiAzikiwe University Teaching Hospital, Nnewi, Nigeria. International Scholarly Research Notices AIDS, Article ID 843794; doi.org/10.1155/ $2013 / 843794$.

32. Ugwu R. and Eneh A. (2013), Factors influencing adherence to paediatric antiretroviral therapy in Portharcourt, South- South Nigeria. Pan Afr. Med. J. 16:30-43.

33. White Y.R.G., Pierre R.B.and Steel-Duncan J. (). Adherence to antiretroviral drug therapy in children with HIV/AIDS in Jamaica. West Indian Med. J., 2008; 57(3): 231-237.

34. Amberbir A., Woldemichael K., Getachew S., Girma B. and Deribe K. Predictors of adherence to antiretroviral therapy among HIV-infected persons: a prospective study in Southwest Ethiopia, BMC Public Health, 2008; 8:265-272.

35. Monjok E, Smesny A, Okokon IB, Mgbere O and Essien EJ (). Adherence to antiretroviral therapy in 
Nigeria: an overview of research studies and implications for policy and practice. HIV/AIDS Research and Palliative Care. 2010; 2: 69-76.

36. Polisset J., Ametonou F., Arrive E., Aho A. and Perez F. Correlates of adherence to antiretroviral therapy in HIV-infected children in Lome, Togo, West Africa. AIDS Behav., 2009; 13: 23-32.

37. Chindedza M., Mutseyekwa F. and ChidemeMunodawafa A. Perceived barriers to accessing and achieving adherence in antiretroviral therapy among HIV patients at a Rural Mission Hospital in Zimbabwe. Nursing European Scientific Journal, 2013; 9(24): 277- 287.
38. Mbirimtengerani N.D., Jere G., Lengu S. and Maluwa A. Factors that influence anti-retroviral therapy adherence among women in Lilongwe Urban Health Centres, Malawi. World Journal of AIDS. 2013; 3: 16-25.

39. Yazdi K., Unterlass G., Kemmler G., Kralovec K., and Aichhorn W. Factors influencing adherence in children and adolescents treated with antipsychotics or antidepressants. Prim. Companion J. Clin. Psychiatry, 2008; 10 (2): 160-161.

40. Iroha E. Esezobor C.I. Ezeaka C., Temiye E.O. and Akinsulie A. Adherence to antiretroviral therapy among HIV-infected children attending a donorfunded clinic at a tertiary hospital in Nigeria. Afr. J.AIDS, 2010; 9(1):25-30. 